\title{
AN EVALUATION OF THE PHYSICAL IMPACT AND STRUCTURAL INTEGRITY OF A GEOTEXTILE SURF REEF
}

\author{
Emma Rendle ${ }^{1}$ and Mark Davidson
}

\begin{abstract}
Geotextile artificial surfing reefs (ASR) are being considered by coastal planners due to their multifunctional potential for coastal protection and habitat provision, as well as additional recreational amenity. However, little research exists on the impact of submerged geotextile structures on the physical marine environment. Europe's first ASR was constructed in 2009 on the south coast of England in Boscombe and is the case study for this paper. This research investigates the claims regarding the structural resilience of an ASR, the modifications to the inshore wave climate and the shoreline response induced by the introduction of an ASR to a system. The Boscombe ASR has suffered from damage, two major geotextile sand filled containers have degraded in this shallow marine environment in two years post-construction. Observations and simulations presented indicate ameliorated wave field leeward of the ASR. There is little shoreline response, given the structures distance offshore, and no salient or widening of the beach has occurred.
\end{abstract}

Keywords: submerged breakwater; artificial surfing reef; multipurpose artificial reefs; geotextile containers

\section{INTRODUCTION}

Europe's first Artificial Surf Reef (ASR) was constructed on the south coast of England in 2009. Gaining much media attention the ASR had been a fierce subject of debate amongst the surfing community with mixed opinions being expressed regarding its success. This paper aims to provide coastal engineers with an objective review of the Boscombe ASR (Fig. 1) through the following objectives; investigating the claims made regarding the modification to the wave field using a numerical model, providing information on the structural integrity of a surf reef and describing the shoreline response to a geotextile submerged reef. Other than an objective assessment of the Boscombe ASR as a surfing facility 6-month post-construction by Davidson (2010), there are no descriptions of the impact of the ASR on the surrounding physical environment. Conclusions of this study are expected to aid coastal planners in decision making regarding the future use of geotextile technology, specifically those considering ASR construction.

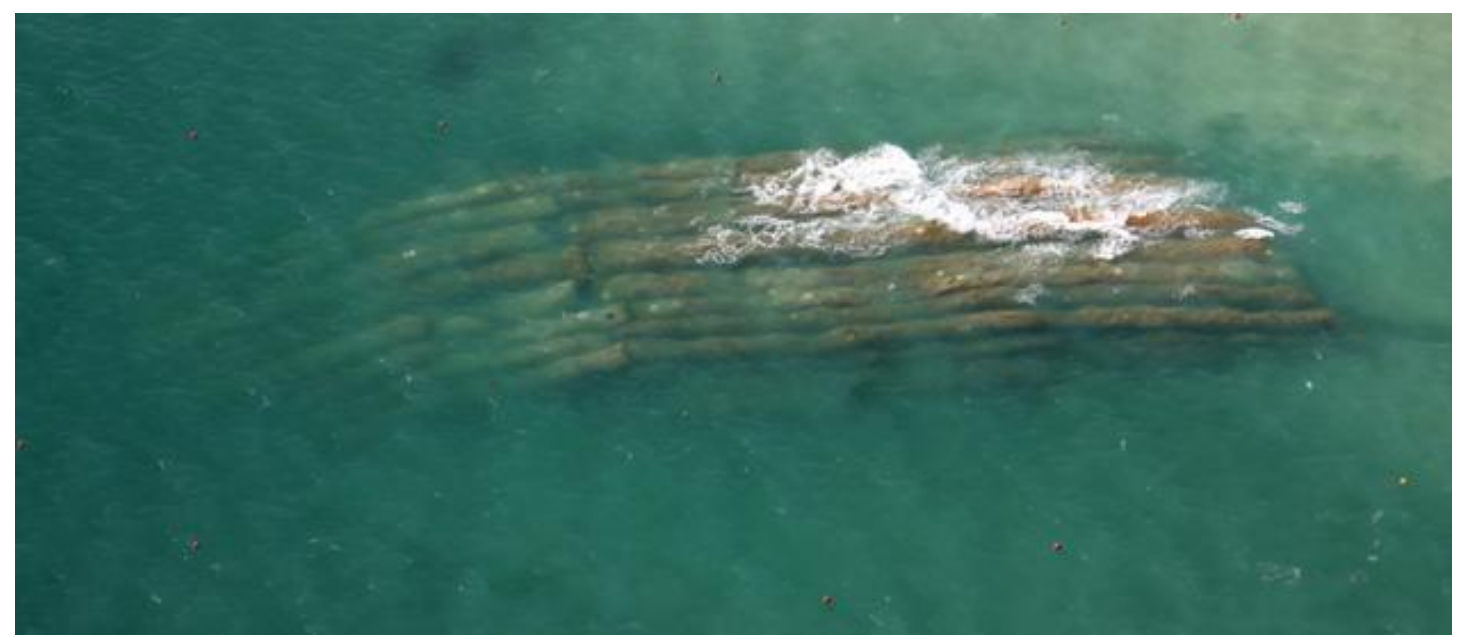

Figure 1. Arial view of the Boscombe Artificial Surfing Reef, UK as it looked post-construction 2009. Top right side of the image is shoreward extent and left side is the seaward extent of the reef.

An ASR is a geotextile submerged structure designed with the intention of altering the local wave field to enhance environmental conditions for surfing thereby providing surf tourism. Artificial reefs essentially replicate the form of natural reefs i.e. sand bars (bar and channel lower beach topography), rocky reefs (remains of cliffs, sheet or rubble) or coral reefs (can be atolls, barrier or fringing reefs). Artificial surf reefs are often claimed to be multifunctional (Mead and Black, 2002) as this enhancement of the environmental conditions is often claimed to not only provide increased tourist

\footnotetext{
${ }^{1}$ School of Marine Science and Engineering, Plymouth University, Drakes Circus, Plymouth, Devon, PL4 8AA, UK
} 
amenity through surfing (ASR Ltd, 2009; Black et al., 2003; Pitt, 2010), but also to provide habitat for the marine ecosystem (Bortone, 2006; Jackson, 2005; Mead, 2009; Moschella et al., 2005; Pratt, 1994) and protect the coast from erosion (Martinelli et al., 2011; Oh and Shin, 2006). Submerged breakwaters are becoming a popular option for coastal protection, mainly due to their low aesthetic impact on the natural environment (Ranasinghe et al., 2010). The reef is designed to mitigate the wave energy to a certain level, allowing water to overtop and circulation at the nearshore to still occur. Unlike other coastal engineering structures (e.g. breakwaters) and traditional artificial reefs, no regulations or protocols of good practice exist for the implementation of ASRs. As a consequence, very little is known on the impacts of such structures in the coastal environment and how they actually perform in promoting their multiple functions.

This new and rapidly developing research area has seen 6 geotextile reefs in existence have all been constructed in the last 12 years. ASRs have been constructed globally with varying levels of success; USA (Borrero and Nelson, 2003; Nelson, 1996) (later removed), Australia (Black and Mead, 2001; Jackson et al., 2007; Jackson, 2005), two in New Zealand (Mead and Black, 1999; Taranaki Regional Council, 2009), India (ASR Ltd, 2010; Tourism Concern, 2012) and most recently the UK (ASR Ltd, 2006; Black et al., 2000). These reefs have employed geotextile technology to form the bulk of the structure, for example Mead (2009). Each reef was constructed based on a detailed design supported by numerical and/or physical model results, indicating a likely (or theoretically likely) improvement in surfing conditions (Shand, 2011). The majority of physical and structural ASR research has been undertaken in the last decade (Scarfe et al., 2009). There are more projects of this kind being considered by practitioners internationally, including proposed ASRs in the USA, Spain, Portugal (ten Voorde et al., 2009), Brazil and Dubai to name but a few.

In 'The Construction, Design and Environmental Effects Report for Boscombe Artificial Surf Reef, UK' (ASR Ltd, 2006) the following claims were made regarding the impacts to the physical coastal environment:

1. Modern geotextiles are durable materials with a postulated life of up to 100 years when submerged, even in a challenging marine environment. The guaranteed life of the geotextile material will depend on the fabric used. By way of example, the material specified for the Noosa ASR in Australia carried a 25-year manufacturer's guarantee.

2. Modelling of sand banks and currents demonstrated that the reef beneficially protects the coast from erosion.

3. In the long-term, no negative impacts are anticipated, as the reef protects the coast in its lee and has no measurable effect away from the reef along the coast. No adverse effect on the existing nourishment and groyne programme is anticipated.

4. There are no adverse rip currents or changes to the currents with the reef present that could strongly affect public swimming or surfers using the reef and beach.

5. The reef provides some shelter from waves at the shore and greatly improves the natural sand banks for surfing.

Derived from claims in the literature, three objectives are put forward: to provide information regarding the ASRs structural resilience, to describing the shoreline response through the analysis of bathymetric surveys, and investigate the modification to the wave field using the numerical model Mike 21. This paper presents an introduction to the study site and the case study Boscombe ASR, following which the methodology, results discussion are given for each of the three objectives. Conclusions are then drawn at the end of the paper.

\section{STUDY SITE}

Boscombe ASR, UK (Figure 2) cost $£ 3.1 \mathrm{~m}$, took 18 months to construct and was completed 03/11/2009. 32 geotextile sand filled containers of various sizes set in opposing directions were positioned by SCUBA divers in two layers and filled with sediment insitu. 

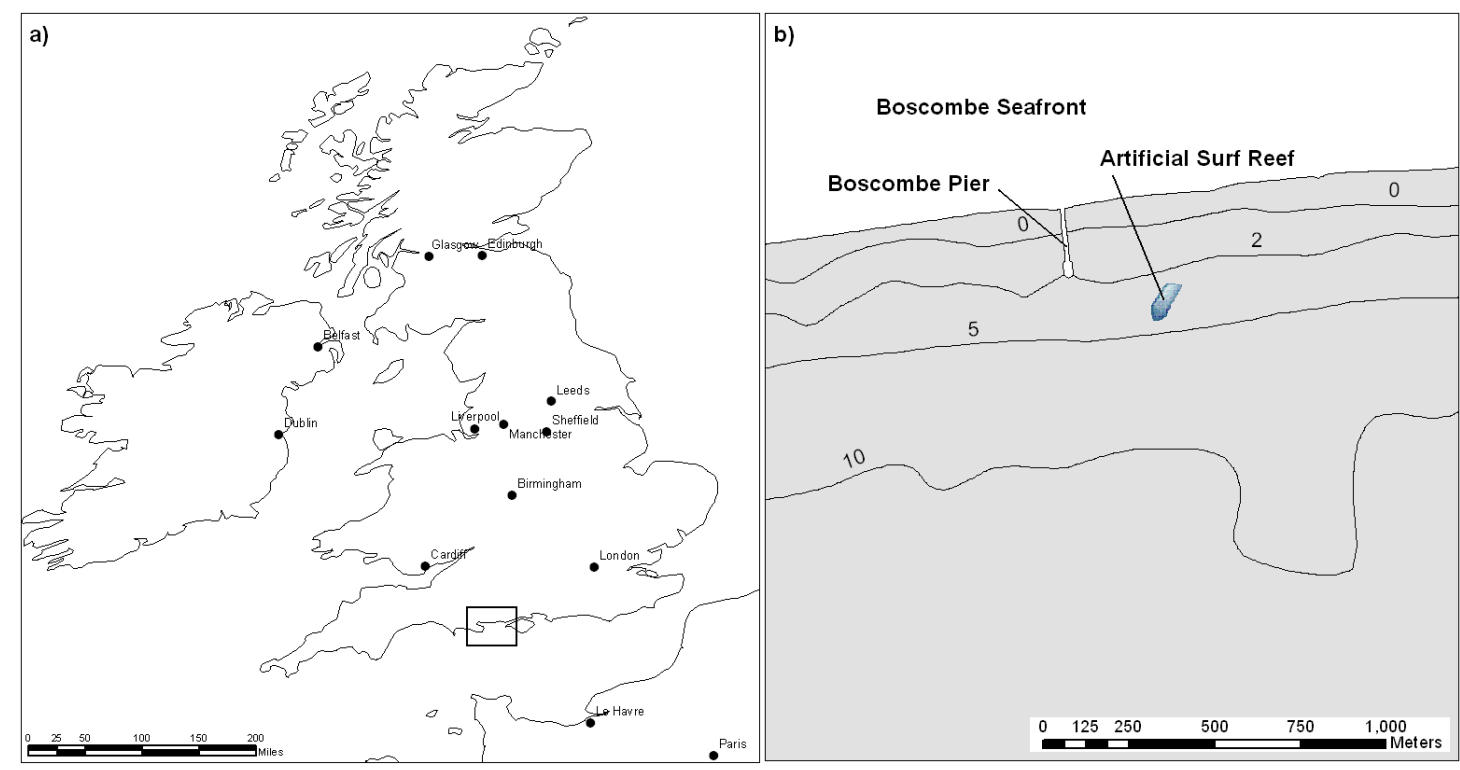

Figure 2. Maps showing a) UK, location of Boscombe on the south coast, and b) Boscombe Artificial Surf Reef location in relation to the coast and pier.

Boscombe and is located on the south coast of England in Poole Bay (Figure 2) and is now more a suburb of Bournemouth than the town it once was. Situated $225 \mathrm{~m}$ offshore in 2.7 to $5 \mathrm{~m}$ depth the footprint covers $45,000 \mathrm{~m}^{2}$. The wave climate can be described as low energy especially in summer months and receives localised storm conditions during the winter months. The significant wave height is $0.5 \mathrm{~m}$, modal period is 4 seconds and modal angle of approach is $191^{\circ}$. Due to Boscombe's locality along the English Channel, much of the long period swell from the Atlantic Ocean is dissipated as it propagates over the continental shelf before it reaches this coastline. Landforms such as Hensbury Head at the southwest extent of the bay also refract and dissipate energy, providing a natural shelter to the coastline. The tides are semi-diurnal and can be described as microtidal, with a maximum spring tidal range of $1.96 \mathrm{~m}$. The intermediate beach has a stabilising groyne field for retaining nourishment sediment.

\section{METHODOLOGY}

\section{Structural resilience and shoreline response}

The structural changes to the geotextile reef and shoreline response were investigated using biannual bathymetry surveys. Data is processed to remove erroneous data points and checks run to ensure observations were realistic. All bathymetry and topography data were interpolated using Matlab, from which the shoreline and contour plots were extracted. Detailed ASR bathymetry data for 2009 to 2011 were made available by the Bournemouth Borough Council for the region of interest and interpolated with bathymetry data, enabled six bathymetries to be investigated.

\section{Modification to the inshore wave field}

In this study, modification to the wave field is simulated using the coupled numerical model Mike 21 by DHI's (Danish Hydraulic Institute). MIKE 21 Spectral Waves module is a 'state-of-the-art' numerical tool for prediction and analysis of wave climate (wind generated and swell waves). Bathymetry was generated from DGPS (Differential Global Positioning System) surveying using spring 2010 data, before damage to the structure was observed, ensuring the environmental impacts of the entire structure were replicated. The model domain covers a 1 x $2 \mathrm{~km}$ stretch of coastline in Poole Bay (Fig. 3). The domain was made wide enough to ensure that boundary effects dissipated prior to the region of interest, groynes were removed from near the boundary as they had a deleterious effect to model stability. 


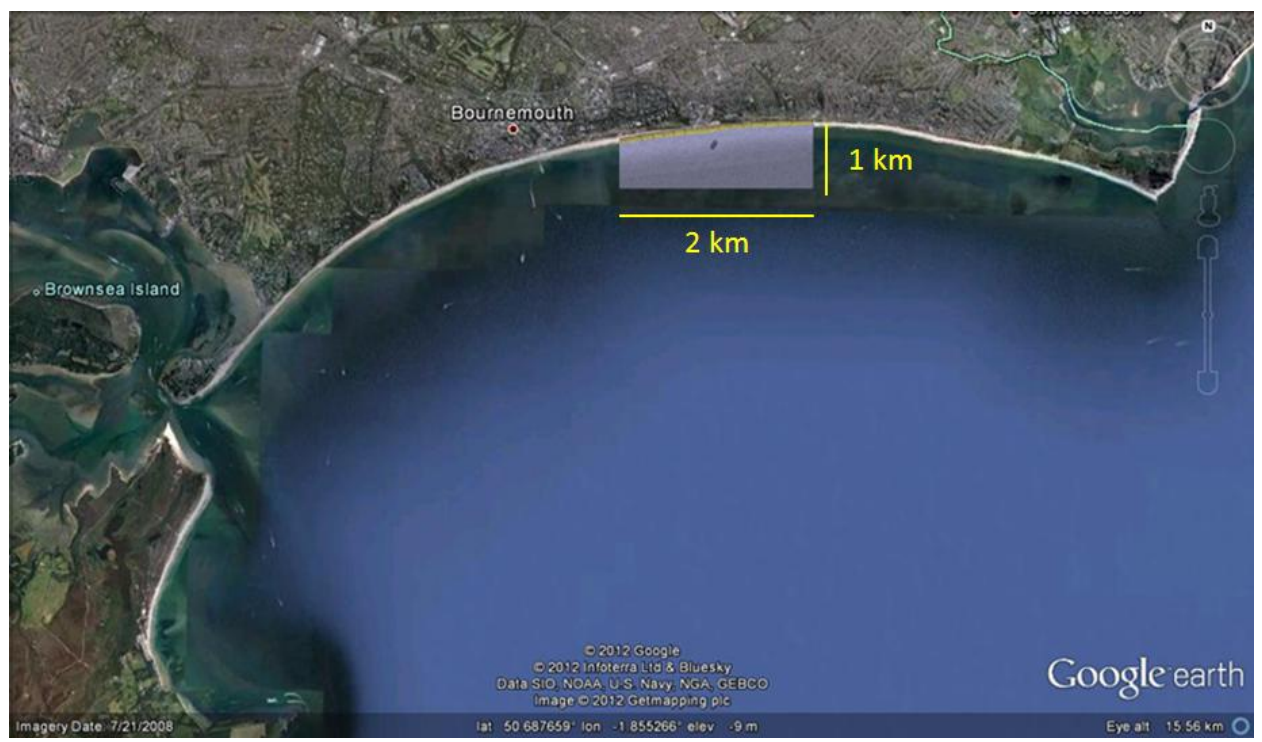

Figure 3. Model domain superimposed on satellite image.

The finite element mesh generated was refined so that shallower areas of interest had finer resolution (Fig. 4). The maximum and minimum element area is 300 to $10 \mathrm{~m}^{2}$, respectively. The artificial surf reef is incorporated as bathymetry and internal boundaries used to preserve the reef's shape in the flexible mesh. The presence of the pier and groynes are included in the model; piles of the pier incorporated in the model set up and groynes are built in to the back wall of the beach. Boundaries are set accordingly, the inshore is closed, east and west are set as 'lateral' boundaries and the offshore boundary is forced with obliquely incident waves. A directional WaveRider MKIII buoy positioned at $10 \mathrm{~m}$ water depth has been collecting data for five years prior to the project. The south boundary of the model has been positioned so that data from the buoy could be used to drive boundary conditions, calibration and validation. Characteristic wave conditions for this area have also been calculated using this data set.

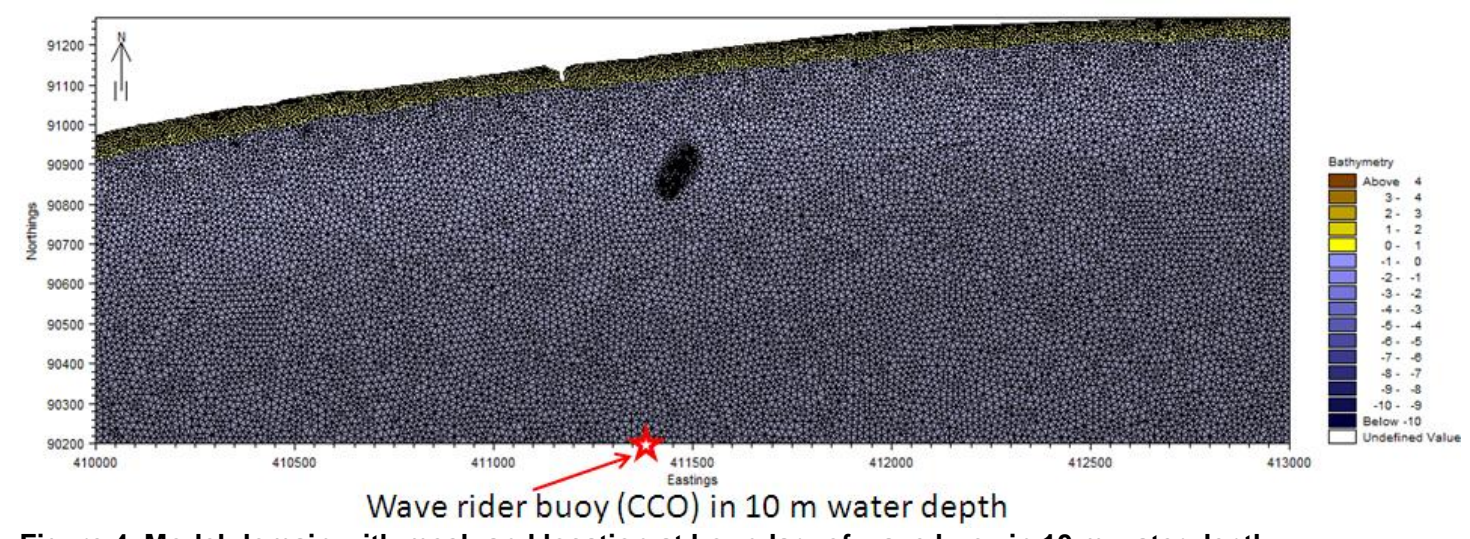

Figure 4. Model domain with mesh and location at boundary of wave buoy in $10 \mathrm{~m}$ water depth

As the beach at Boscombe is highly popular with water sports users all year round a nearshore rig to position data recorders was not appropriate. Data on wave attenuation in the leeward area of the ASR was collected by pressure transducers (PTs) attached to the ends of four groynes during spring tide low for one calendar month January 2011. Two PTs were placed leeward of the ASR on groynes 23 and 24 and for comparison two were placed on groynes 27 and 28 (Fig. 5). The latter were chosen as they represented a similar stretch of 'natural' beach without the influence of the reef. This data was collected in order to validate the numerical model. 


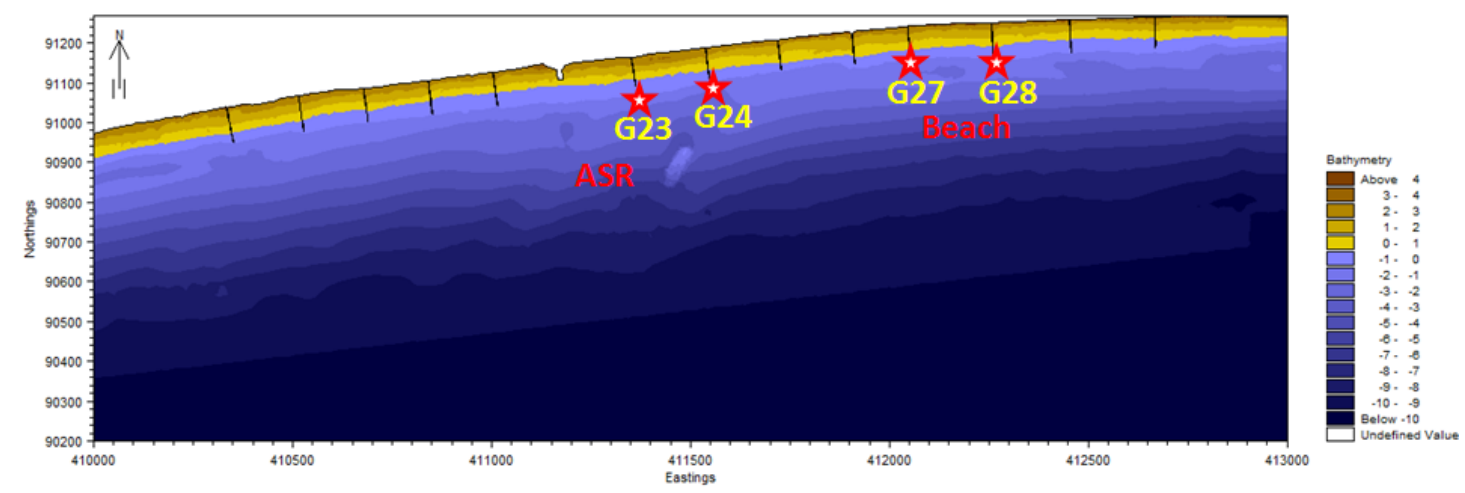

Figure 5. Model domain with pressure transducer locations highlighted

Validation of the Mike 21 model (Fig. 6) was carried out using wave buoy data for the same time period as the measured data by the pressure transducers was collected. Comparison of the measured (red) and modelled (blue) wave data is good. The $10 \mathrm{~m}$ wave buoy data (black) have been included to provide evidence that the pressure transducers and model are accurately representing the nearshore environmental conditions. The model is considered to be resolving dissipation of wave energy appropriately due to the accuracy of the model prediction. Root mean squared error (RMSE) of between $0.10 \mathrm{~m}$ and $0.14 \mathrm{~m}$ for the four data comparisons offers strong confidence in the model. Regression analysis provides further confidence in the data allowing us to predict 78 to $85 \%$ of the variance in the measured data with the model. Sensitivity analysis on a sensible range in gamma was conducted however the best fit was the default of 0.78 .

Leeward of ASR
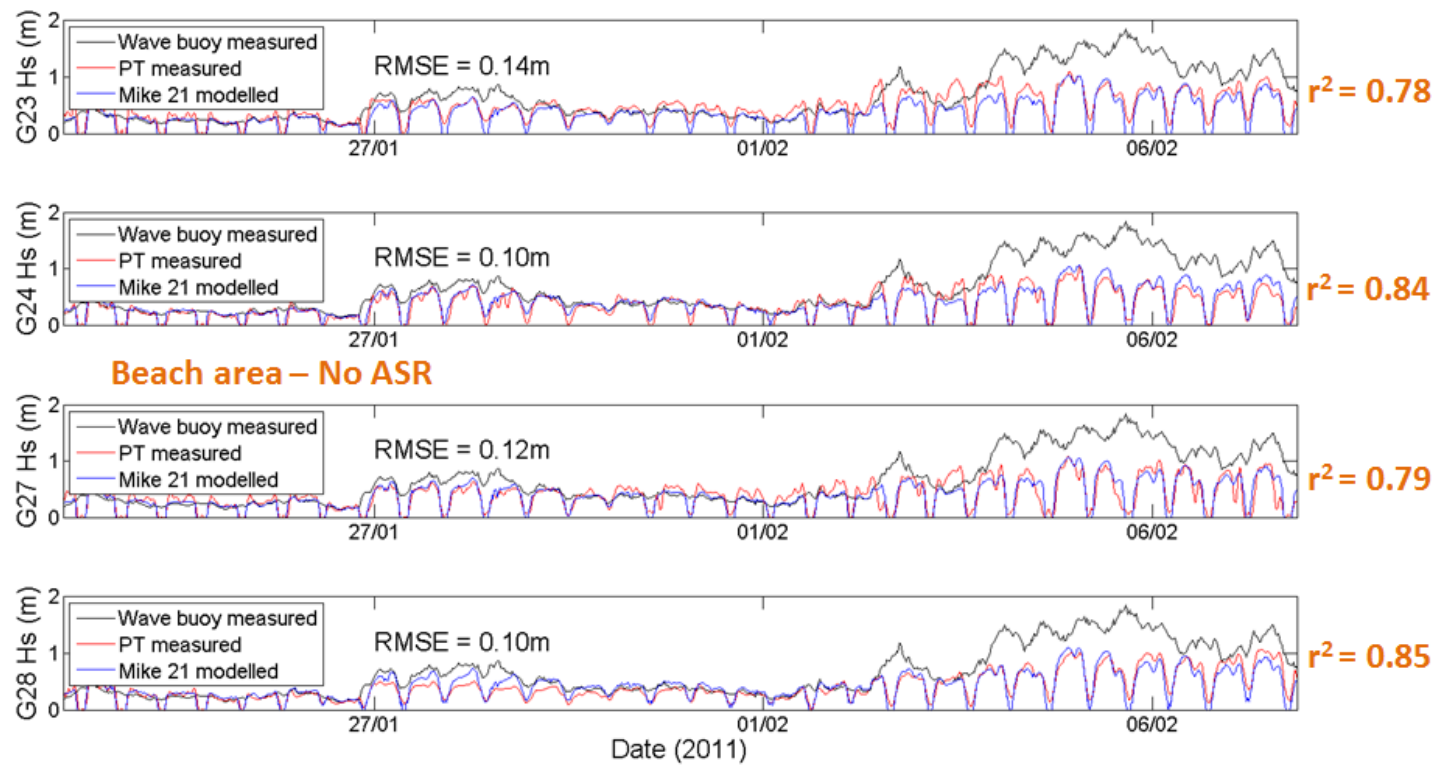

Figure 6. Measured data from the pressure transducers (PT) plotted against the modelled results with the wave buoy data included for reference. With groynes 23 and 24 leeward of the ASR and groynes 27 and 28 in an area of beach considered to be unaffected by the ASR.

In order to investigate the claim that the ASR would create a sheltered area for swimmers and bathers we wanted to understand if there were conditions under which the reef may focus or dissipate wave energy and therefore increase or decrease breaker height leeward of the ASR $\left(\mathrm{H}_{\mathrm{a}}\right)$. This was compared to the breaker height at the beach $\left(\mathrm{H}_{\mathrm{b}}\right)$ under the equivalent conditions. Theoretically, it is logical that small amplitude waves propagating in deep water (around high-tide) will focus wave amplitude at leeward of the ASR $(A>1)$ due to the absence of dissipation and refraction. Conversely, higher amplitude waves propagating in shallower water will be dissipated by the reef leading to reduced wave height at the leeward beach $(\mathrm{A}<1)$. Environmental conditions were tested through a variety of test 
cases with different wave heights, periods and water levels. Wave attenuation coefficient (A) is considered to be a function of wave height $(\mathrm{H})$, tide, wave period $(\mathrm{T})$ and direction $(\theta)$ as given by:

$$
\mathrm{H}_{\mathrm{a}} / \mathrm{H}_{\mathrm{b}}=\mathrm{A}=f(\mathrm{H}, \text { tide, } \mathrm{T}, \theta)
$$

A matrix of model tests was planned spanning the parameter space of the dependent variables in equation 1; in all 180 simulated scenarios were generated. All tests were run at an angle of oblique wave approach $\theta=173^{\circ}$, as the effect of angle of approach simply shifts the effect to the east or west of the ASR and wave direction has limited bearing on the mode of shoreline response (Ranasinghe et al., 2010). Due to the typically low energy environment at Boscombe, $\mathrm{H}$ ranged from 1 to $0.125 \mathrm{~m}$ in five increments, tide represented the spring tidal range 1 to $-1 \mathrm{~m}$ in nine increments, and $\mathrm{T}=5,6,7$ and $12 \mathrm{~s}$ were investigated. An assessment of the wave climate was carried out using the model in the area shoreward of the structure and a beach area that is considered unaffected by the structure. The model was run using typical wave height conditions for Boscombe $(\mathrm{H}$ ranging from 1 to $0.125 \mathrm{~m}$ in five increments), the period was set at the average for Boscombe, $6 \mathrm{~s}$ and the tidal range was $2 \mathrm{~m}$. The results were averaged for a typical tidal cycle.

To investigate the mode of shoreline change at the Boscombe reef site, work by Ranasinghe et al (2010) was replicated. In this work, physical and numerical model simulation of a theoretical reef were examined to establish under what conditions the mode of shoreline response to a submerged structure might be accretive or erosive. They concluded that when a 2-celled circulation pattern was present divergent currents were created leading to erosion at the shoreline. When a 4-celled circulation pattern was present convergent currents were created leading to accretion at the shoreline (Fig. 7).
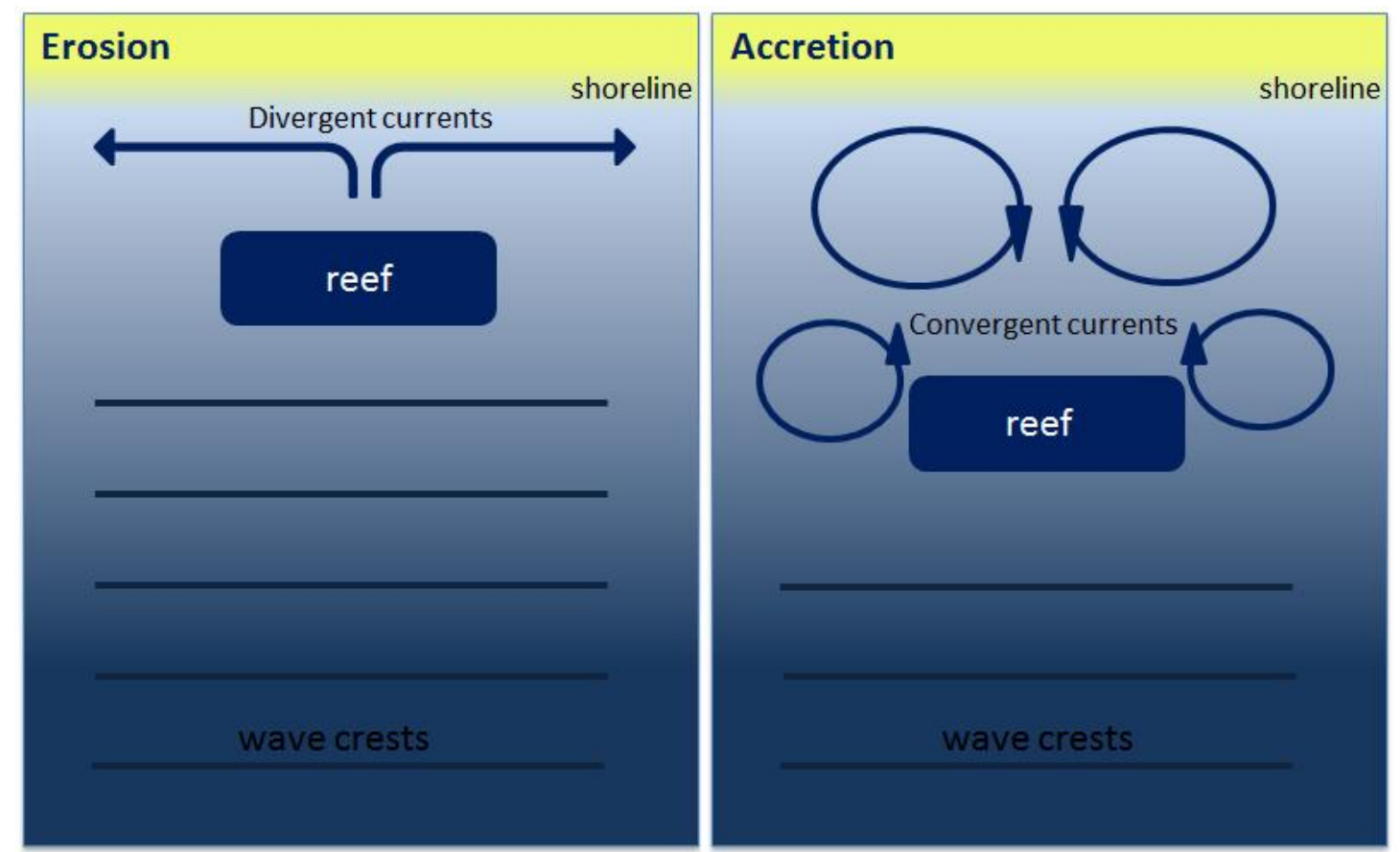

Figure 7. Example of submerged breakwater induced circulation patterns leading to: (a) shoreline erosion and (b) shoreline accretion, taken from Ranasinghe et al. (2010). The arrows indicate the general circulation patterns found through physical and modelling tests. The cross-shore distance from the shoreline to structure $\left(X_{b}\right)$ and breaker height $\left(H_{b}\right)$ effect the pattern of circulation; Ranasinghe et al. (2010) found that increasing $X_{b}$ (from $100 \mathrm{~m}$ to $300 \mathrm{~m}$ ) and $H_{b}$ (from $2 \mathrm{~m}$ to $4 \mathrm{~m}$ ) produced the 4-celled circulation pattern.

\section{RESULTS}

\section{Structural resilience}

Boscombe ASR has suffered damage; two major geotextile containers have degraded in this shallow marine environment in two years post-construction. A timeline of events is presented (Fig. 8) as a guide for this section; it highlights the main dates of construction and completion, when structural faults were discovered in bathymetry surveys and the ASRs eventual closure to the public. 


\section{Summer 2008 \\ Summer 2009 \\ October 2009 \\ Winter 2010/11 \\ April 2011 \\ April 2011 \\ April 2012 Present situation Uncertain future for the ASR, it remains closed \\ $1^{\text {st }}$ Layer of SFCs \\ $2^{\text {nd }}$ Layer of SFCs \\ Construction completed \\ Hydraulic reworking of sediment noted \\ SFC failure recorded by annual survey \\ Reef closed after concerns for safety \\ Further SFC failure recorded by annual survey}

Figure 8. Timeline of event from the start of construction in 2008 to the present (2012) situation. Geotextile sand filled containers (SFCs) were filled insitu by SCUBA divers over consecutive summers with construction being officially completed by $02 / 10 / 09$.

The upper images (Fig. 9) illustrate where cross-sections of the ASR were taken through all surveys. The lost geotextile container is highlighted; a $4 \mathrm{~m}$ gap between geotextile containers and a depression in crest height of $2 \mathrm{~m}$. This container is significant as the structure now has an undulating crest; it was deemed dangerous by the council and could possibly trap surfers or swimmers in turbulent waters on the reefs crest. The ASR was subsequently closed to the general public in April 2011.

The lower images (Fig. 9) show the same cross-section over a two-year period every 6 months starting in October 2009. This first profile is taken shortly after the reef is declared finished, the undulations of the geotextile containers are obvious yet relatively smooth. After the 2009 winter, changes in the shape of the reef are evident in the May 2009 survey; sediment has been reworked in the containers leading to some areas of containers experiencing increased crest height whilst others have lost crest height. There are notable changes to the surrounding seabed level from the first to the second survey, erosion in the western and north and accretion to the east and southern areas. Few changes are seen over the 2010 summer months as wave energy is considerably reduced and the October 2010 survey is similar to May. Following the 2010/11 winter further hydraulic reworking of sediment in the geotextile containers is evident as the ASR shape is changed from the original construction and design. The lost container is evident as the large two meter deviation from the other three profiles. Further damage discovered by the April 2012 bathymetry survey, although these data have not been made available by the council; the geotextile container to the right of the gap is now also lost making the gap between containers up to $10 \mathrm{~m}$.
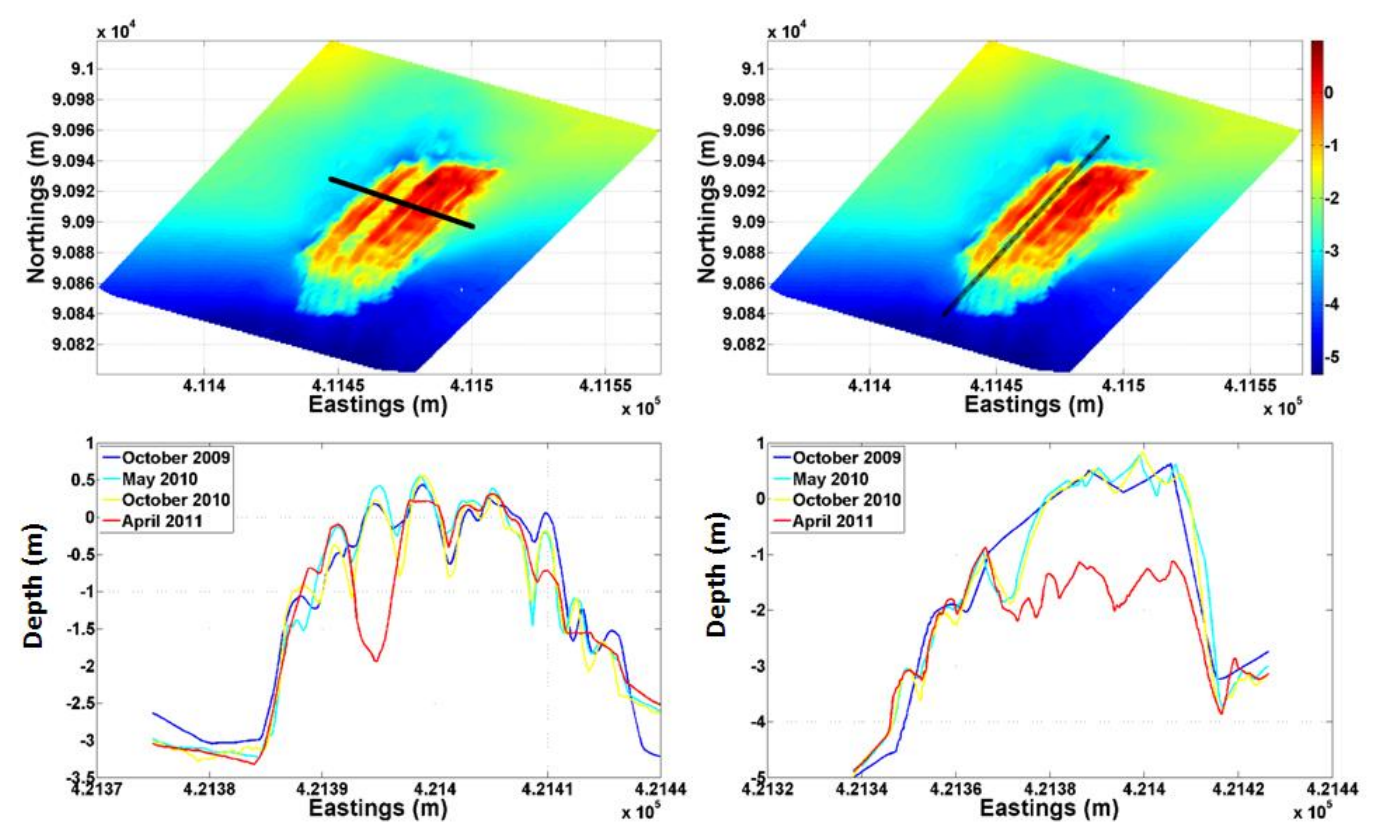

Figure 9. Cross-sections of the ASR bathymetry in April 2011 (above) with example profiles for the associated plots (below). Profiles taken through the ASR from four Channel Coast Observatory bathymetry surveys. 


\section{Shoreline Response}

In three years since construction there has been no shoreline significant response to the Boscombe ASR; the small fluctuations $(<0.2 \mathrm{~cm})$ that are observed are not different from elsewhere along the coastline, or out of line with normal seasonal fluctuations (Fig. 10). The mode of shoreline response is neither accretive not erosive. No accretion has been observed at the shoreline and no salient (or tombolo) formation has occurred in its lee despite claims that the reef could aid the retention of sand replenishment. A nourishment scheme at Boscombe created the present beach topography, once settled the shoreline has been held from April 2008 (before construction commenced) to April 2011 (2.5 years post-construction). In the UK, mean sea level (MSL) is equivalent to Chart Datum, Newlyn, UK (0 m contour in Fig. 10).

Offshore where there ASR induces the largest modifications to the wave filed, there has been some significant changes to the bathymetry since the introduction of the ASR. There is localised scouring at the base of the structure creating a steepening of the bathymetry towards the beach in the leeward area of the ASR. The $-3.5 \mathrm{~m}$ contour has eroded near the base of the reef (Fig. 10) and migrated over $50 \mathrm{~m}$ towards the shoreline. The overall migration of the contour landward $(<20 \mathrm{~m})$ is the result of the reworking and settling of the beach nourishment material as some is inevitably lost.

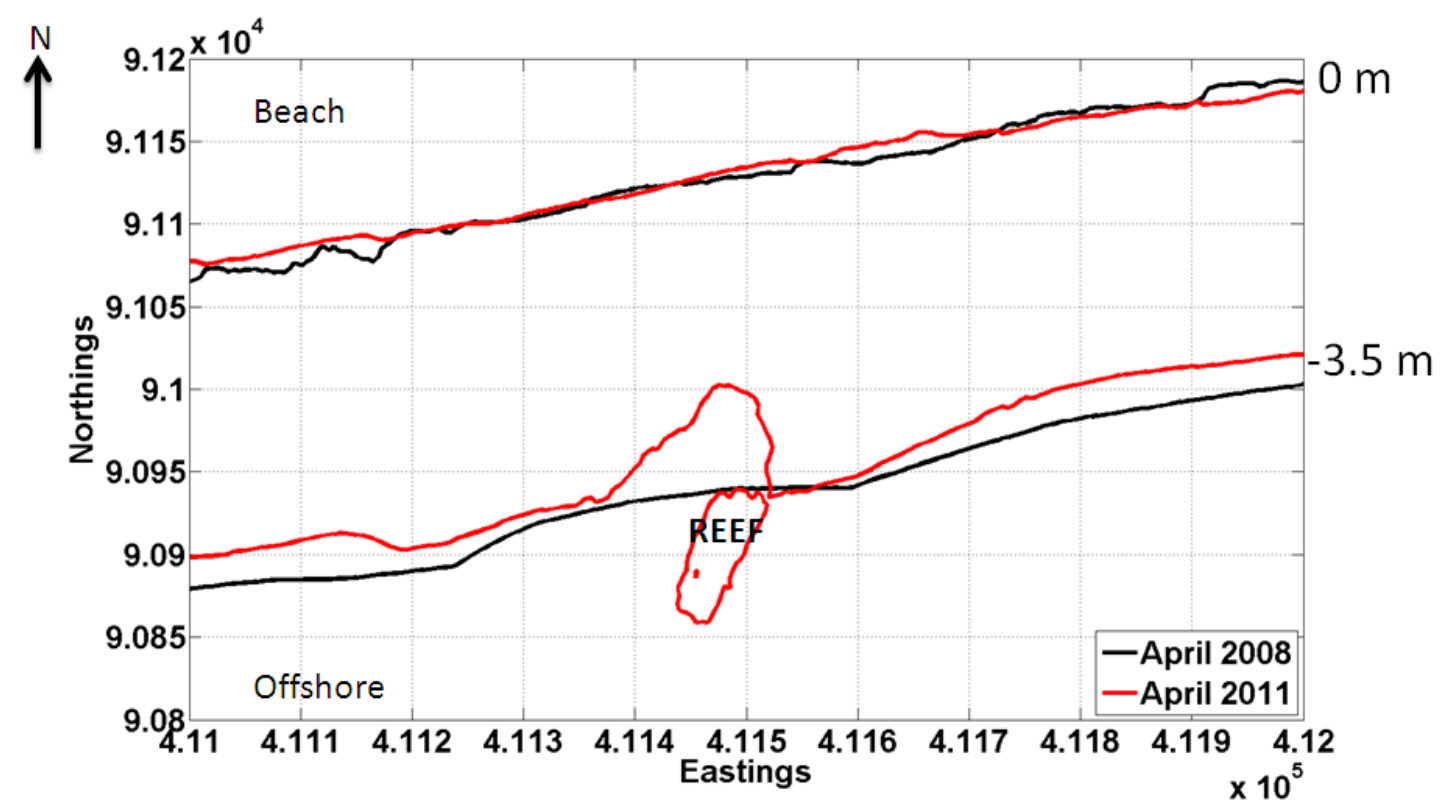

Figure 10. Shoreline ( 0 metre contour) and contour in topography (-3.5 metres) to highlight mode of shoreline change and fluctuations in bathymetry.

\section{Modification to the wave field}

Consistent to theoretical predictions, the reef attenuation coefficient (A) increases proportionately with water depth but inversely with wave height. The filled contour plots (Fig. 11) show that attenuation (A) does not approach, nor exceeded 1 (bright yellow). When plotting the breaker height in the leeward area of the ASR $\left(\mathrm{H}_{\mathrm{a}}\right)$ over the breaker height at an area of beach unaffected by the $\operatorname{ASR}\left(\mathrm{H}_{\mathrm{b}}\right)$ we see that under all conditions tested there is attenuation of wave energy. Under no conditions are wave breaker heights leeward of the reef greater than the offshore wave height at the boundary. 


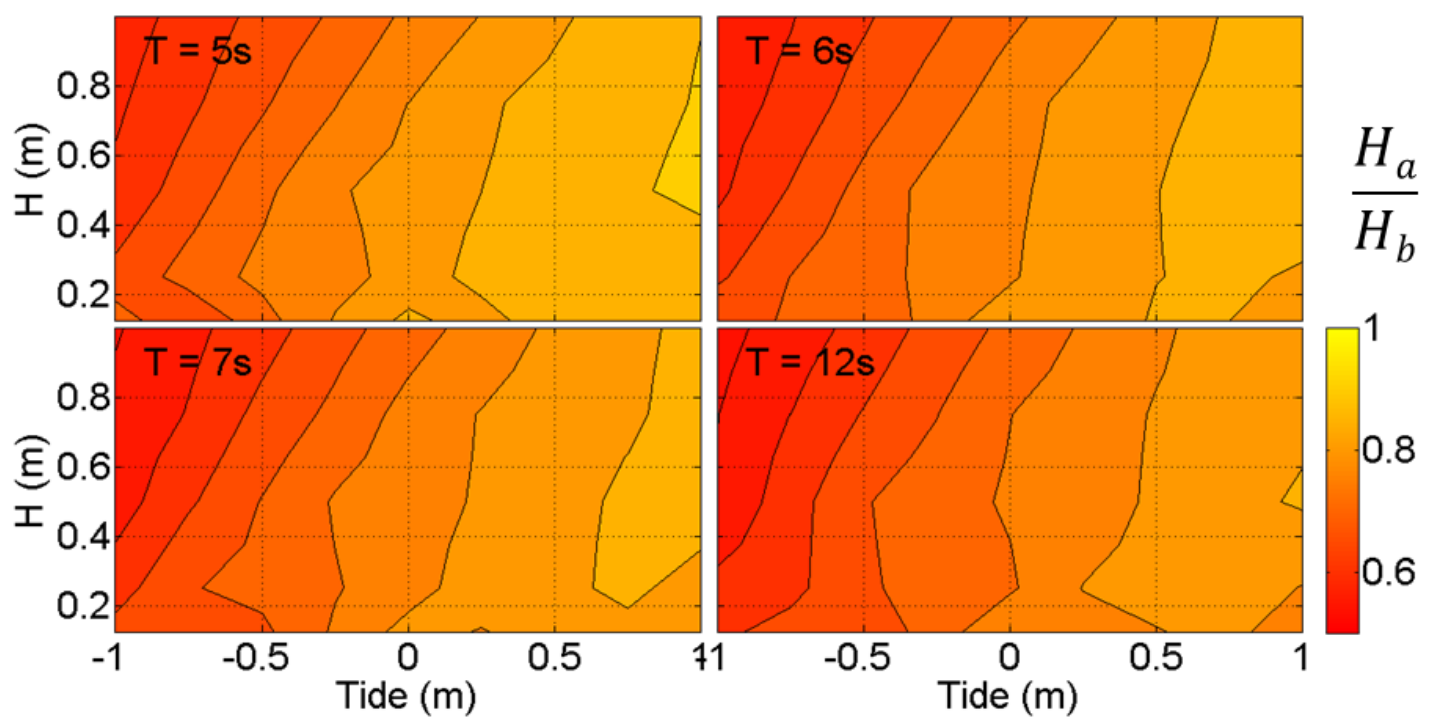

Figure 11. A filled contour plot of the height at breaking leeward of the ASR $\left(\mathrm{H}_{\mathrm{a}}\right)$ over the height at breaking at the beach $\left(H_{b}\right)$ for $1 \mathrm{~m}$ wave heights, tidal range $2 \mathrm{~m}$ and period $5,6,7$ and $12 \mathrm{~s}$.

The resulting current speeds from averaging the model output over an approximated tidal cycle are given for five wave heights typically experienced at the Boscombe ASR (Fig. 12). This shows the effect of wave induced currents only and does not include the effect of tides. Little response at the shoreline is simulated however there are areas of divergence highlighted during the larger wave simulations near the structure. There is diversion in current direction when $\mathrm{H}_{\mathrm{s}}=1 \mathrm{~m}$ and $\mathrm{H}_{\mathrm{s}}=0.75 \mathrm{~m}$, indicated by the larger black arrows (Fig. 12), highlighting areas of potential erosion. There is minimal divergence or convergence of currents and therefore no likely shoreline response when wave heights are simulated for $0.5,0.25$ and $0.125 \mathrm{~m}$. Water velocity near the coast is typically $>0.2 \mathrm{~ms}^{-1}$. The set-up of gradients in wave height near the ASR cause increased water velocity over the reef, ranging from 0.7 to $0.2 \mathrm{~ms}^{-1}$.
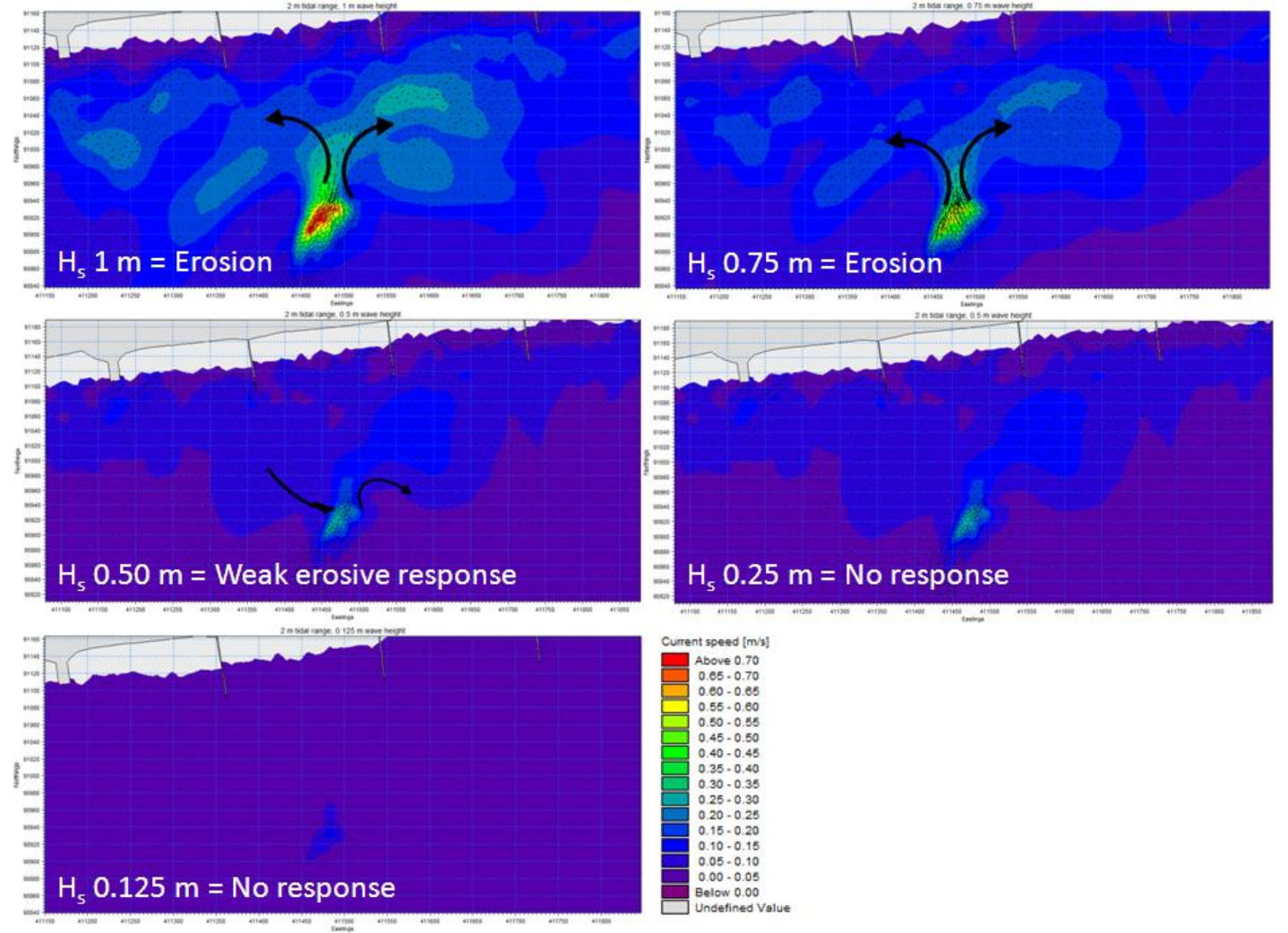

Figure 12. Wave induced model simulation over 12 hour tidal cycle 


\section{DISCUSSION}

\section{Structural resilience}

The stability of the Boscombe ASR has been questioned since construction began. The geotextile containers have shown to fail in the final inspection report (Richards, 2009); two apparent "tears" with temporary tie-wrap stitching were located and several anomalies were highlighted which may be defects where the reef has been patched in places. The bags were repaired however these weaknesses remain a serious concern for the continued integrity of the structure. Verbal accounts of the geotextile containers suffering from wave impacts and associated sediment movement have been noted during questionnaire based research with surfers and members of the public (Rendle and Rodwell, 2012); after the first winter post construction it was noted that the structure was suffering from hydraulic reworking of the sediment, and that there might be strain on the structure in 2010. The largest geotextile containers are approximately 5 meters in diameter and $70 \mathrm{~m}$ long (there are only 8 containers of this size and they make up the bulk of the structure). A post-winter inspection (April 2011) of the ASR highlighted one of these was damaged; the ASR lost 80 tons of sediment. An adjacent geotextile container was lost from the main crest of the structure after 2.5 years (in 2012). The council claim that a boat propeller caused the damage to the first geotextile container and they have an insurance claim pending based on that belief (Bournemouth Borough Council, 2012). It was hoped that the first container would be replaced (at the cost of the insurer) in August 2011 whilst other remedial works were taking place, however neither works nor repairs took place due to a break down in relations between the construction company and the council. At time of writing (August 2012) the ASR is still closed to the public due to safety concerns surrounding the damaged area and the potential for trapping of swimmers or surfers.

Certain claims made in the original design documentation for Boscombe ASR incited investigation into the integrity of the structure and the geotextile containers. It was stated that "modern geotextiles are durable materials with a postulated life of up to 100 years when submerged, even in a challenging marine environment" and "the guaranteed life of the geotextile material will depend on the fabric used. By way of example, the material specified for the Noosa ASR in Australia carried a 25-year manufacturer's guarantee" (ASR Ltd, 2006). This understandably led the council to believe that they were investing in a product that would last for a minimum lifespan of 25 years and that the structure would remain intact during that time. Hydrological reworking of the sediment within the geotextile containers, alongside the compression and settling of sediment has altered the structure from its original shape and from its design. Due to the initial loss of the geotextile container in 2011 there was up to $2 \mathrm{~m}$ change in the crest height of the ASR. There are some signs of erosion at the landward and westward sides of the structure although these are considered minimal.

This area of coastline is relatively sheltered from open ocean swell as energy is removed as waves propagate over the continental shelf. Localised storm waves are frequent in the winter period and likely to cause localised reworking of beach sediment. The damage caused to the reef is a combination of damage from the hydraulic reworking of sediment within the containers applying strain on the material and seams, as well as some propeller damage. It is important to understand fully the localised wave climate and therefore the pressures exerted on the geotextiles during the design phase. Geotextile submerged breakwaters or ASRs are inherently hazardous near shipping routes or recreational boat users due to navigational dangers due to the delicate nature of the geotextile containers. Additionally, to ensure there is no potential for damage by propellers, there needs to be more comprehensive signage at an ASR if there are recreational boats in the inshore area so that inexperienced powerboat users correctly understand the cardinal marker buoys. These buoys need to be fixed properly, there were incidents of buoys being lost during storm events and the Boscombe ASR went unmarked during winter months.

\section{Shoreline response}

Regardless of the fact that the ASR was not built for coastal defence, there were claims (ASR Ltd, 2006) that the modeling of sand banks and currents demonstrated that the reef beneficially protects the coast from erosion. Claims were made that might have incited an expectance of beach widening; in the sheltered lee of the reef, the beach will become wider by up to $40 \mathrm{~m}$ (ASR Ltd, 2009). Alongside which, no negative impacts were anticipated, as the reef was claimed to protect the coast in its lee and have no measurable effect away from the reef along the coast (ASR Ltd, 2006). There is little shoreline response, given the structures distance offshore and no salient (or tombolo) formation or widening of the beach has occurred. According to the empirical theory given by Ranasinghe and Turner (2004) the magnitude of shoreline change relates to structure length, crest height and cross-shore distance offshore. 
Circulation induced by gradients in wave height at the ASR are a significant distance offshore $(>200 \mathrm{~m})$ therefore do not have an effect on the shoreline. The Boscombe ASR is far enough offshore to have minimal interaction with the shoreline. This can also be observed in the bathymetry surveys (Fig. 10) where the shoreline contour has not migrated since construction began in 2008; there has been no observed accretion at the shoreline over the past three years. However, some erosion has been observed in the bathymetry, there is localised scour and erosional affects near to the structure between the 3 and 4 $\mathrm{m}$ contours.

\section{Modification to the wave field}

To investigate the claim that Boscombe ASR will provide a safe, sheltered area for bathing DHI's Mike 21 was used to simulate the beach and provided a useful tool to assess how the ASR is impacting the wave climate at Boscombe. An assessment of the wave climate in the area shoreward of the structure and an area away from the structure was carried out thereby simulating the height at breaking in a scenario with an ASR $\left(\mathrm{H}_{\mathrm{a}}\right)$ and without an ASR $\left(\mathrm{H}_{\mathrm{b}}\right)$. For all the scenarios tested the Boscombe ASR proves to dissipate wave energy and provide an ameliorated wave field shoreward of the structure. In terms of wave height, the ASR therefore fulfils the claim that the area leeward of the reef is safe for bathers; certainly it is no more dangerous at the nearshore than the rest of the beach area.

The model was also used to investigate the current patterns surrounding the ASR; of particular interest is the return of water mass around the reef and the potential for generation of rip currents. In order to gauge how this would manifest over a tidal cycle simulations were averaged over a 12 hour cycle for varying wave heights, from $1 \mathrm{~m}$ to $0.125 \mathrm{~m}$ (Fig. 11). The results show no response to the wave currents under the smaller wave conditions of $0.125,0.25$ and $0.5 \mathrm{~m}$ wave height. Although weak, divergent currents are highlighted in the 0.75 and $1 \mathrm{~m}$ wave heights scenarios. Given the small size of the reef and its distance offshore is far enough that any erosional effects are not observed at the shoreline or in the beach topography.

To further explain the wave driven currents at the ASR, typical conditions for Boscombe ( $1 \mathrm{~m}$ wave height, $6 \mathrm{~s}$ period, angle of approach is shore normal, $173^{\circ}$ ) are shown (Fig. 13), simulated at three different water levels $(1,0$ and $-1 \mathrm{~m})$ to reflect spring tidal conditions. Additional manually placed directional arrows to highlight the circulation pattern at the ASR and possible gyres. In lower water level $(-1 \mathrm{~m})$ conditions a 4-celled circulation pattern is apparent. With increased water level $(0 \mathrm{~m})$ the concentric secondary cells are lost and a 2-celled circulation pattern of divergent currents can be observed. When the water level is at $-1 \mathrm{~m}$ and $0 \mathrm{~m}$ the crest of the ASR is emergent and the circulation pattern is enhanced compared to when the crest is submerged. Simulation of the water level at $1 \mathrm{~m}$ generates a weaker 2-celled circulation pattern of convergent currents and associated with accretion.

These results are consistent with physical and numerical model work by Ranasinghe et al (2010) where they illustrate 2- to 4-celled circulation patterns occurring around submerged breakwaters (Fig. 7) with varying wave height and increasing distance offshore. Modelling the water level at its highest extent shows that the 2-celled pattern is weakest in velocity at the high tide. The velocities are weakened in the higher water level $(1 \mathrm{~m})$ scenario compared to the relatively stronger velocities in low $(-1 \mathrm{~m})$ water level scenario. The results of the simulations of Boscombe ASR reflect observations in the literature and, although weak due to the limited local wave climate, reveal this circulation pattern acting at Boscombe nearshore coastal environment. Further to this, the steepening of the bathymetry leeward of the ASR (Fig. 10) can be explained by the presence of a gyre at the location of the erosion.

Mike 21 simulations have been derived using wave driven conditions solely. Future investigation will combine tidally driven currents into the hydrodynamics to understand the rip currents at the ASR. Due to the presence of the reef no return flow near the bottom can compensate for the water masses accumulated behind the reef due to wave set up. The return flow is hampered by the incoming waves, enhanced longshore currents and tidal effect could therefore evolve with an associated erosion potential. 

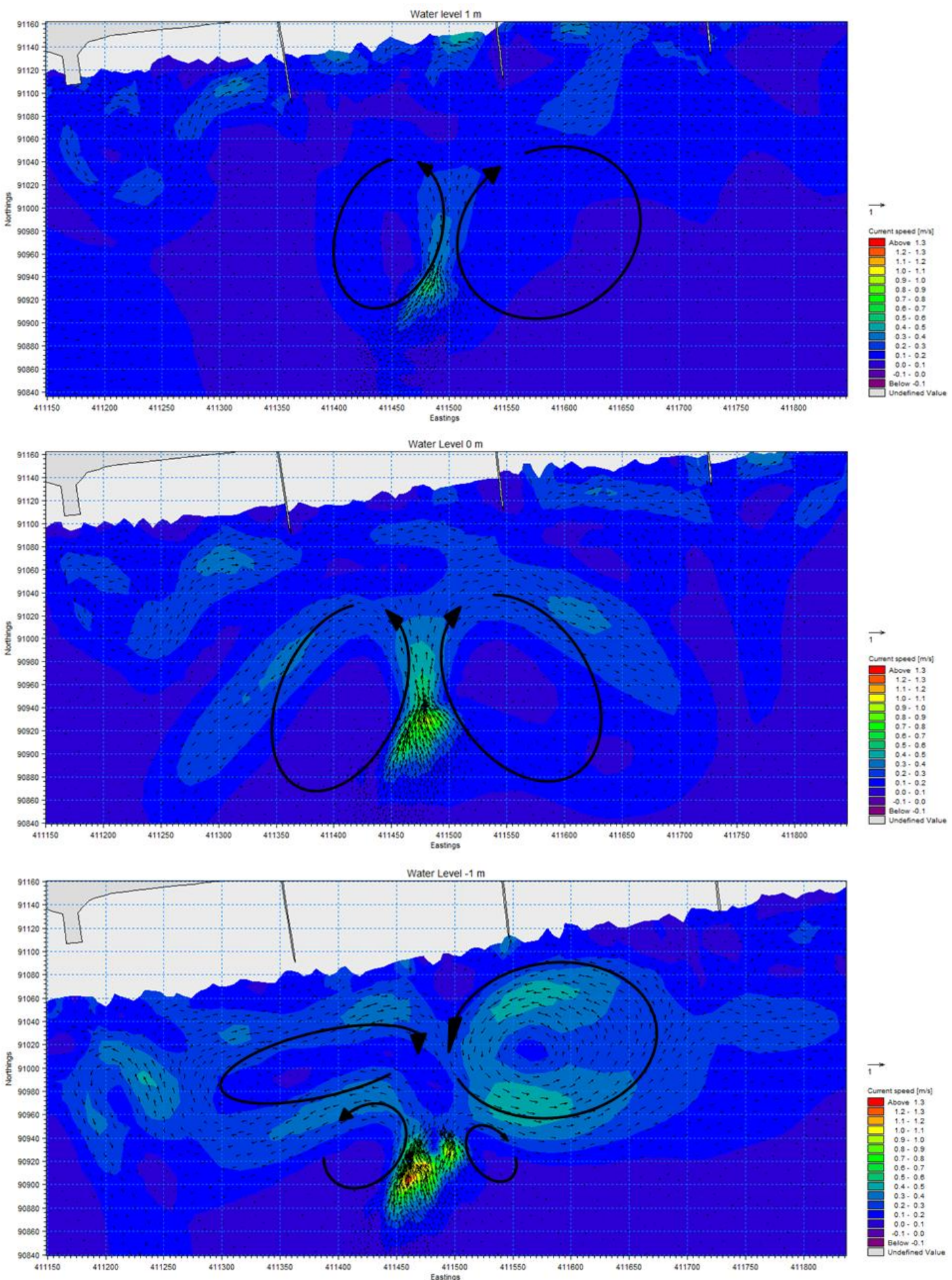

Figure 13. Examples of Mike 21 model output for $1 \mathrm{~m}$ wave height at 6 second period at various water levels with the change in circulation and velocity being dependent on crest height. Water level at $1 \mathrm{~m}$ (upper), $0 \mathrm{~m}$ (centre) and $-1 \mathrm{~m}$ (lower). Heavy black arrows added to highlight circulation patterns. 


\section{CONCLUSIONS}

- The structural resilience of the Boscombe ASR is fundamentally flawed, the geotextile containers that have degraded in this shallow marine environment, even under low energy wave conditions.

- In contrast to the original design claims (ASR Ltd, 2006), the Boscombe ASR has not protected the coast from erosion. There is little shoreline response leeward of the ASR given the distance offshore. No salient or widening of the beach has occurred. However, erosion has been observed in the bathymetry causing steepening towards the beach in the lee of the reef.

- In terms of wave height, observations and simulations indicate ameliorated wave field leeward of the ASR, supporting the claim that the reef does provide a sheltered zone for swimmers and bathers. Future research plans to evaluate tidal currents, explore the resulting hydrodynamics and the potential for rip current generation. Storm profile change using DGPS data to address shoreline change observations during storms and recovery periods.

\section{ACKNOWLEDGMENTS}

This work was funded by the University of Plymouth Research Studentship Scheme. The authors wish to thank; Bournemouth Borough Council for providing access to bathymetry records, Danish Hydraulic Institute (DHI) for the loan of and instruction in Mike 21, RBR Ltd. for the loan of pressure transducers, Channel Coast Observatory (CCO) for detailed bathymetry and wave buoy data, and British Oceanographic Data Centre (BODC) for tidal data. Maps reproduced with permission from SeaZone Chartered Raster product with permission of the controller of from Her Majesty's Stationary Office and SeaZone Solutions Ltd.

\section{REFERENCES}

ASR Ltd, 2006. Boscombe surfing reef: Construction design and environmental effects. Prepared for leisure and tourism, bournemouth borough council, ASR Ltd. Raglan, New Zealand.

ASR Ltd, 2009. Multi-purpose reefs for coastal protection and prosperity, ASR Ltd, Raglan, New Zealand.

ASR Ltd, 2010. Kovalam coastal protection. http://www.asrltd.com/projects/kovalam-coastalprotection.php, Accessed on, 02/02/12

Black, K. and Mead, S., 2001. Design of the gold coast reef for surfing, beach amenity and coastal protection: Surfing aspects. Journal of Coastal Research, Special Issue 29: 115-130.

Black, K.P., Blenkinsopp, S.T., Mead, S., Weight, D. and Gerrish, B., 2003. Artificial surfing reefs for erosion control and amenity: Theory and applicaiton, Posford Haskoning Ltd.

Black, K.P., Mead, S. and Jackson, A., 2000. Beach amenity options and coastal protection at bournemouth, Artificial Surfing Reefs Ltd. Ragland, New Zealand.

Borrero, J.C. and Nelson, C., 2003. Results of a comprehensive monitoring program at pratte's reef. www.surfrider.org, Accessed on, 21/11/09

Bortone, S.A., 2006. A perspective of artificial reef research: The past, present and future. Bulletin of Marine Science, 78 (1): 1-8.

Davidson, M., 2010. 6-month interim report: Performance of boscombe surfing reef, bournemouth borough council, University of Plymouth, UK.

Jackson, L., Corbett, B., Tomlinson, R., McGrath, J. and Stuart, G., 2007. Narrowneck reef: Review of 7 years of monitoring results.

Jackson, L., Reichelt, R. E., Restall, S., Corbett, B., Tomlinson, R., and McGrath, J., 2005. Marine ecosystem enhancement on a geotextile coastal protection reef - narrowneck reef case study. Proceedings of 29th International Conference on Coastal Engineering, Lisbon, Portugal, 3940-3952.

Martinelli, L., Zanuttigh, B., De Nigris, N. and Preti, M., 2011. Sand bag barriers for coastal protection along the emilia romagna littoral, northern adriatic sea, italy. Geotextiles and Geomembranes, 29(4): 370-380.

Mead, S., 2009. Multiple-use options for coastal structures: Unifying amenity, coastal protection and marine ecology. Reef Journal, 1(1): 291-311.

Mead, S. and Black, K., 1999. A multipurpose, artificial reef at mount maunganui beach, new zealand. Coastal Management 27: 335-365.

Mead, S. and Black, K., 2002. Multi-purpose reefs provide multiple benefits - amalgamating coastal protection, high quality surfing breaks and ecological enhancement to maximise user benefits 
and development opportunities. SASIC 2002, Holiday Inn Conference Centre, Ventura, California.

Moschella, P.S. et al., 2005. Low-crested coastal defence structures as artificial habitats for marine life: Using ecological criteria in design. Coastal Engineering, 52(10-11): 1053-1071.

Nelson, C.E., 1996. A coastal managment case study in el segundo, california., Duke University Durham, North Carolina.

Oh, Y.I. and Shin, E.C., 2006. Using submerged geotextile tubes in the protection of the e. Korean shore. Coastal Engineering, 53(11): 879-895.

Pitt, A., 2010. Surfing ramps. www.surfingramps.com.au, Accessed on, 05/01/2010

Pratt, J.R., 1994. Artificial habitats and ecosystem restoration - managing for the future. Bulletin of Marine Science, 55(2-3): 268-275.

Ranasinghe, R., Larson, M. and Savioli, J., 2010. Shoreline response to a single shore-parallel submerged breakwater. Coastal Engineering, 57(11-12): 1006-1017.

Ranasinghe, R. and Turner, I.L., 2004. Processes governigh shoreline response to submerged breakwaters: Multi-function structures - a special case review. Proceedings of 29th International Conference Coastal Engineering, Lisbon, Portugal, 1984.

Rendle, E. and Rodwell, L., 2012. Artificial surf reefs: A preliminary assessment of the potential to enhance a coastal economy. Marine Policy Special Edition, In Preparation.

Richards, P., 2009. Post construction survey report, boscombe surf reef, boscombe, dorset. 09/147, Commercial and specialised diving Ltd., Ferndown, Dorset.

Scarfe, B.E., Healy, T.R. and Rennie, H.G., 2009. Research-based surfing literature for coastal management and the science of surfing - a review. Journal of Coastal Research, 25: 539-557.

Shand, T., 2011. Making waves? A rational review of artificial surfing reef projects. Shore and Beach, 79(3): 12-16.

Taranaki Regional Council, 2009. Opunake artificial reef monitoring programme 2005-2009.

ten Voorde, M., do Carmo, J.S.A. and Neves, M.G., 2009. Designing a preliminary multifunctional artificial reef to protect the portuguese coast. Journal of Coastal Research, 25(1): 69-79.

Tourism Concern, 2012. Artificial reef built off kovalam a failure. http://www.tourismconcern.org.uk/tourismwatch-southindia/reports/view/2, Accessed on, 02/02/2012 